\title{
Early Applications of DMT in Arabian Gulf Area - Three Case Studies
}

\author{
Sharif $\operatorname{Emad}^{(\bowtie)}$ \\ GTC LAB, Geotechnical Engineering, e.construct, Dubai, UAE \\ emad.sharif@econstruct.ae,emad.sharif@gtc-lab.com
}

\begin{abstract}
DMT was used for three main applications in famous projects in Dubai, UAE and in Duqm Port in Sultanate of Oman in the Arabian Gulf. The $1^{\text {st }}$ two applications were conducted in man-made sandy earthfill embankments formed by dredging from the sea bed and stabilized by deep ground improvement. The recent correlations of S. Marchetti to incorporate the DMT stress history parameter $\mathrm{K}_{\mathrm{D}}$ for CPT-based CRR was used to confirm post-compaction CPT-based liquefaction analysis in the Duqm Site, whereas DMT was used in Dubai site to confirm the over consolidated nature of upper sandy fill soil that was previously Vibro-Compacted (8-10 years). On the other hand, the design of large diameter flexible steel oil storage tanks is based on controlled \& strict, edge settlement requirements. Without DMT, the estimates of soil modulus are made based on SPT or CPT tests resulting in conservative estimates, and suggesting the need for deep ground densification/improvement. Site specific correlation was developed for a large site between DMT based M and CPT tip resistance (qc) indicating at least 50\% increase over the CPT based M.
\end{abstract}

\section{Introduction}

DMT was only recently introduced for practical use in Dubai and the Gulf Area in General. This paper describes three main early applications of DMT in main projects. The several man-made islands in Dubai and other places, present a convenient area of application of DMT and SDMT for both assessment of the deep man made earth fill, design and control of deep ground improvement procedures and assessment of liquefaction potential. Further, the construction of large diameter oil storage flexible steel tanks presents another important area where DMT can provide valuable information to accurately assess the settlement of tanks.

This paper presents some of the recent applications of DMT in this area.

\subsection{Man-Made Islands/Embankments}

Construction on artificial islands or embankments by dredging and filling is very common in the Arabian Gulf region for different purposes. 


\subsubsection{Background on Man-Made Islands \& Embankments Construction and Stabilization}

Several Man-made Islands were constructed along the shore line of Dubai. The first was Palm Jumeira Island having an approximate diameter of $8 \mathrm{Kms}$ as shown in Fig. 1.

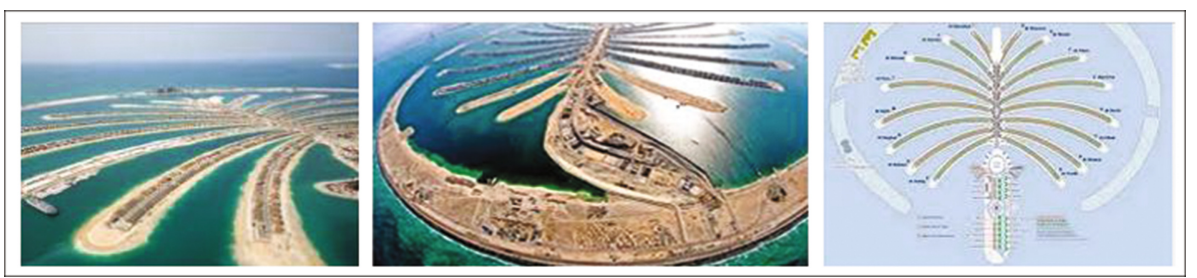

Fig. 1. Typical shapes of man-made islands

The photos in Fig. 2 show part of the Commercial berth site in Duqm Port in Oman, proposed to accommodate several industrial facilities for the port.

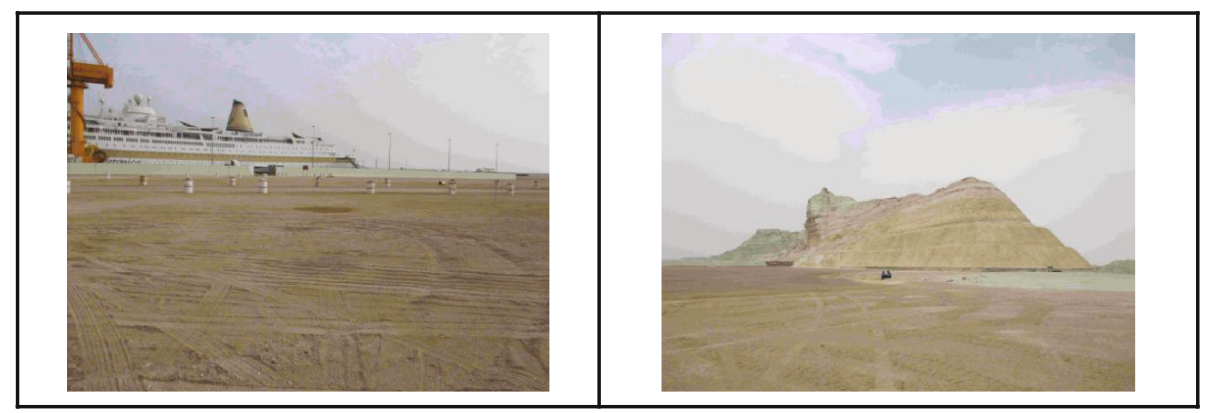

Fig. 2. Commercial Berth - Duqm New Port

The islands/embankments were constructed with silty sands dredged from adjacent sea bed and laid by hydraulic filling with heights ranging between 12-18 $\mathrm{m}$ above original sea level as shown in Fig. 3.

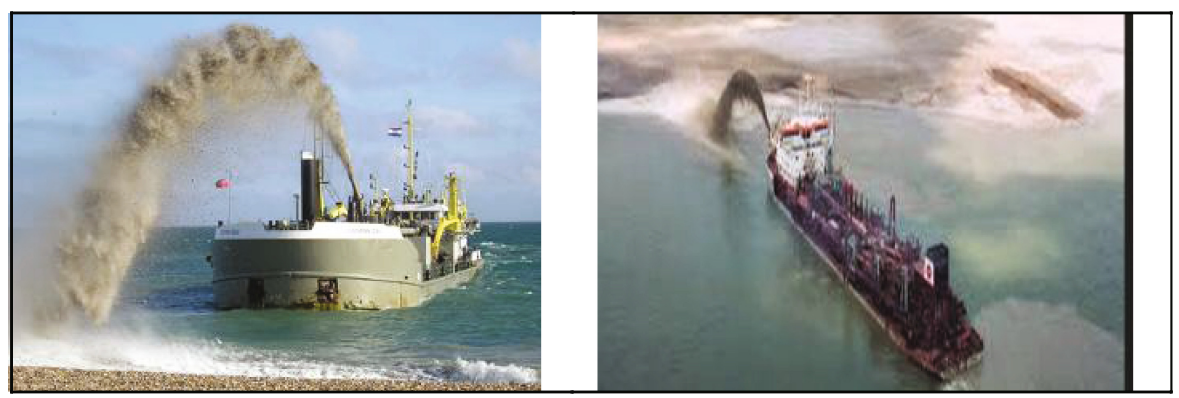

Fig. 3. Typical photos of sand dredging operations 


\subsubsection{Ground Densification and Verifications}

Stabilization and densification of the upper sandy fill is essential to improve its Engineering performance and mitigate hazards such as liquefaction and high differential settlements and long term creep movements.

Common Methods used are Vibro Compaction/Replacement and Dynamic Compaction/RIC for shallow sand depths. Vibro Compaction is most widely and commonly used method although other methods were also used.

Verification of VC works is typically based on Pre and post-compaction CPT measurements and zone loading tests in some cases.

The use of Robertson (2009) CPT-based Profiling (SBT) is very effective to establish the localities of high silt content/high friction ratio which are not likely compactable.

\subsubsection{Actual Performance}

Several roads, buildings on shallow and deep foundations exist since more than 8-10 years by today and performing very well as indicated in Fig. 4 .
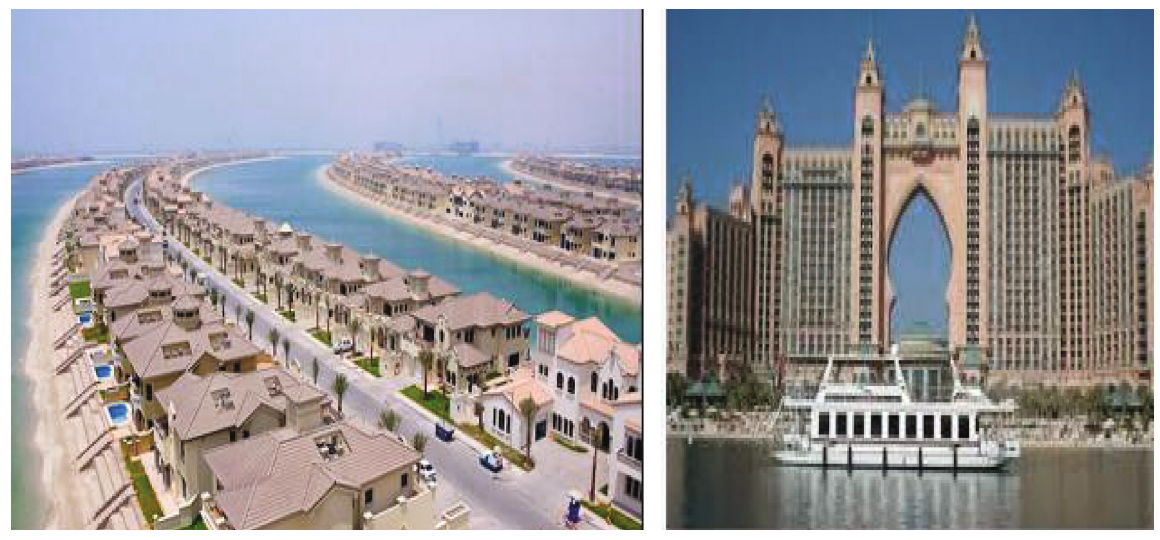

Fig. 4. Typical light weight and heavy structures in PJ

No published data exists about actual performance of the foundation, however the observed evidence indicates very well and satisfactory performance of the compacted earth fill.

Testing showed remarkable stiffness and strength increase with aging. Fills tested after several years of laying are stiffer than young fills.

\subsection{Case 1: Confirming CPT-Based Liquefaction Analysis in Port of Duqm in Oman}

The Duqm area lies along the coasts of the Indian Ocean, about $600 \mathrm{~km} \mathrm{SW}$ of Muscat, as shown in Fig. 5, the Capital City of the Sultanate of Oman. 


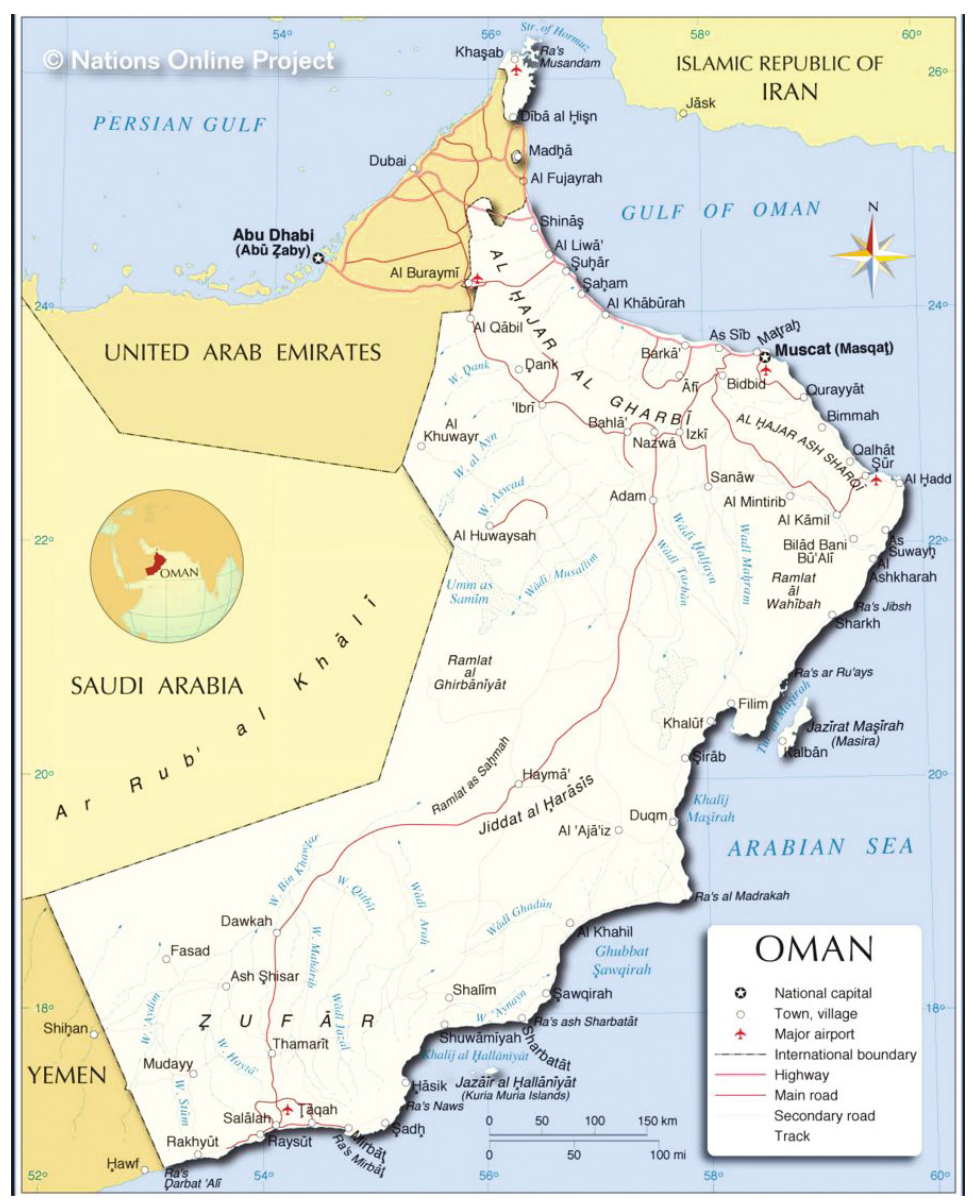

Fig. 5. Map of Oman showing location of Duqm

The area is intended to accommodate one of the largest Oil Ports in the Middle East with all associated facilities as sea port, airport, dry dock, oil refinery, Storage Terminals, infra-structures like roads, rail way, bridges, buildings and residential villas etc. that are under construction or on the anvil.

\subsubsection{Description of DMT/CPT Application}

A main component of the port facilities is the Commercial Berth which is made up of thick reclaimed sandy fill by dredging from the sea bed and hydraulic filling. The berth is $>250 \mathrm{~m}$ in width and more than $1500 \mathrm{~m}$ in length extending from the coastal line into the sea. The typical soil profile indicates a thick (typically 12-18 m), slightly silty to silty fine sand (reclaimed soil) on top of a thin sea bed layer of silt/Clay soil that is underlain by bedrock of very to extremely weak claystone. 
The use of shallow foundations to support the many proposed light to moderately heavy structures within the area of the Commercial Berth requires satisfaction of both liquefaction mitigation and acceptable settlement performance criteria, including control of potential differential settlement.

The Berth was investigated with large number of widely spaced boreholes with SPT testing conducted at 1 to $1.5 \mathrm{~m}$ intervals in each borehole as part of technical feasibility and initial risk assessment and planning of the port. Later, a more detailed investigation was conducted within the site of a typical project that lies within the mid-zone of the Commercial Berth and which is proposed for cement silos and concrete mixing plant. The subsurface conditions are indicated in the generalized subsurface profile in Fig. 6, which shows the upper sandy fill of about $15 \mathrm{~m}$ depth, underlain by thin sea bed layer of clayey soil followed by bedrock of claystone, as indicated in Fig. 6.

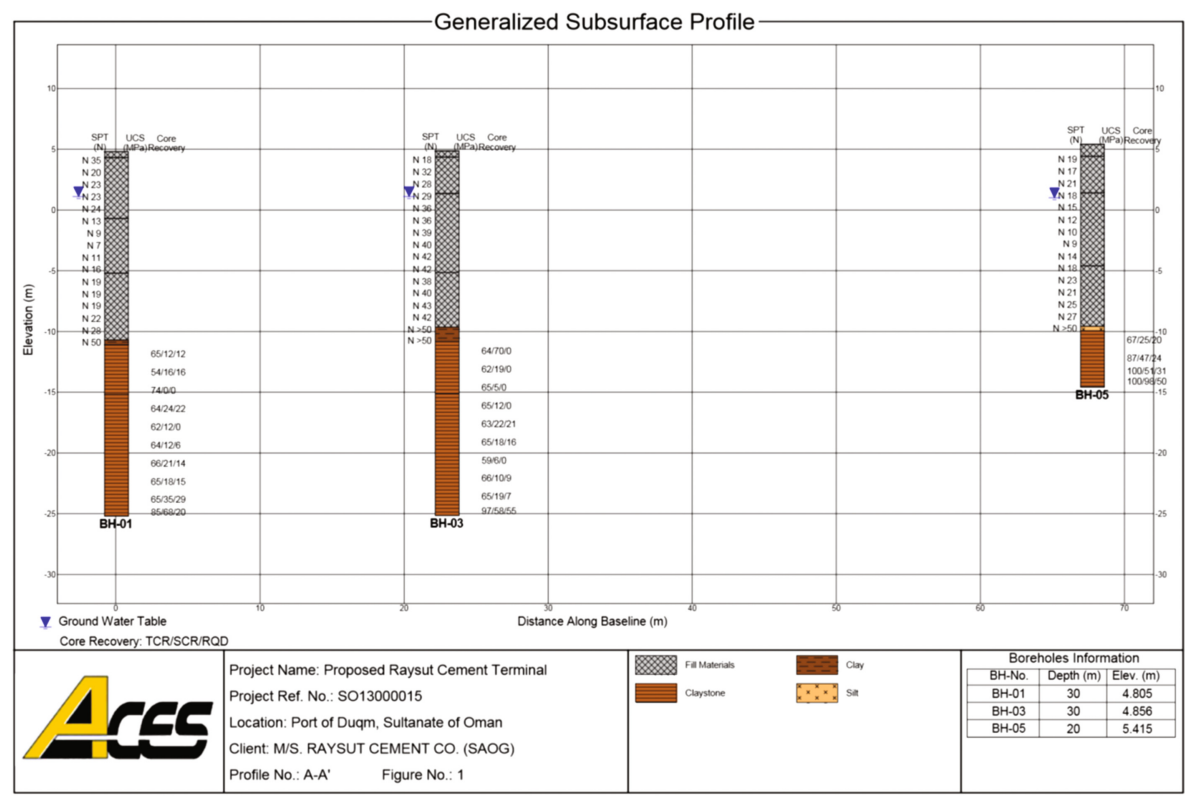

Fig. 6. Generalized subsurface profile - Duqm site

The SPT tests results obtained within 5 test borings, has indicated large stiffness variations and presence of weak zones. This is clearly indicated in Fig. 7 of SPT vs. elevation. 


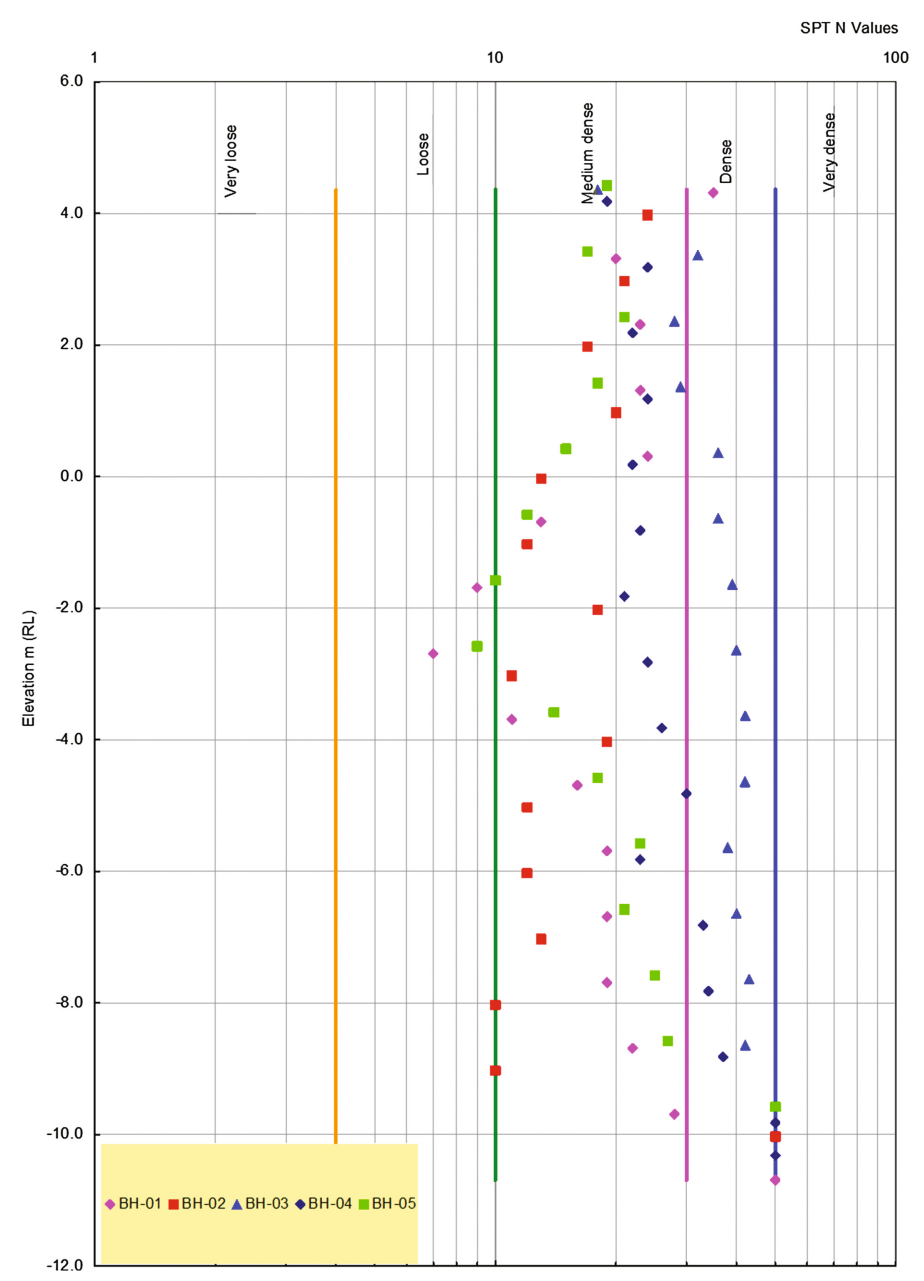

Fig. 7. SPT vs. Elevation - Duqm site

The obtained SPT results, suggested that deep ground improvement is necessary. Vibro compaction was found to be technically feasible, time and cost effective method to achieve the necessary targets. Pre compaction - CPT tests were conducted and used to assess the liquefaction potential and plan the VC works. The results showed the site is liquefiable and weak, and therefore VC works were conducted. $1^{\text {st }}$ round VC: The typical layout of triangular grid of VC points is shown in Fig. 8.

Verification included post-compaction CPTU tests at three locations as indicated in the above layout. At each location, 2 pair of post-compaction CPT tests were conducted, at $1 / 3^{\text {rd }}$ spacing from the poker point and at centre of spacing of a typical triangular grid. Typical post-compaction CPT results and CPT - based liquefaction analysis results are shown in Fig. 9. 


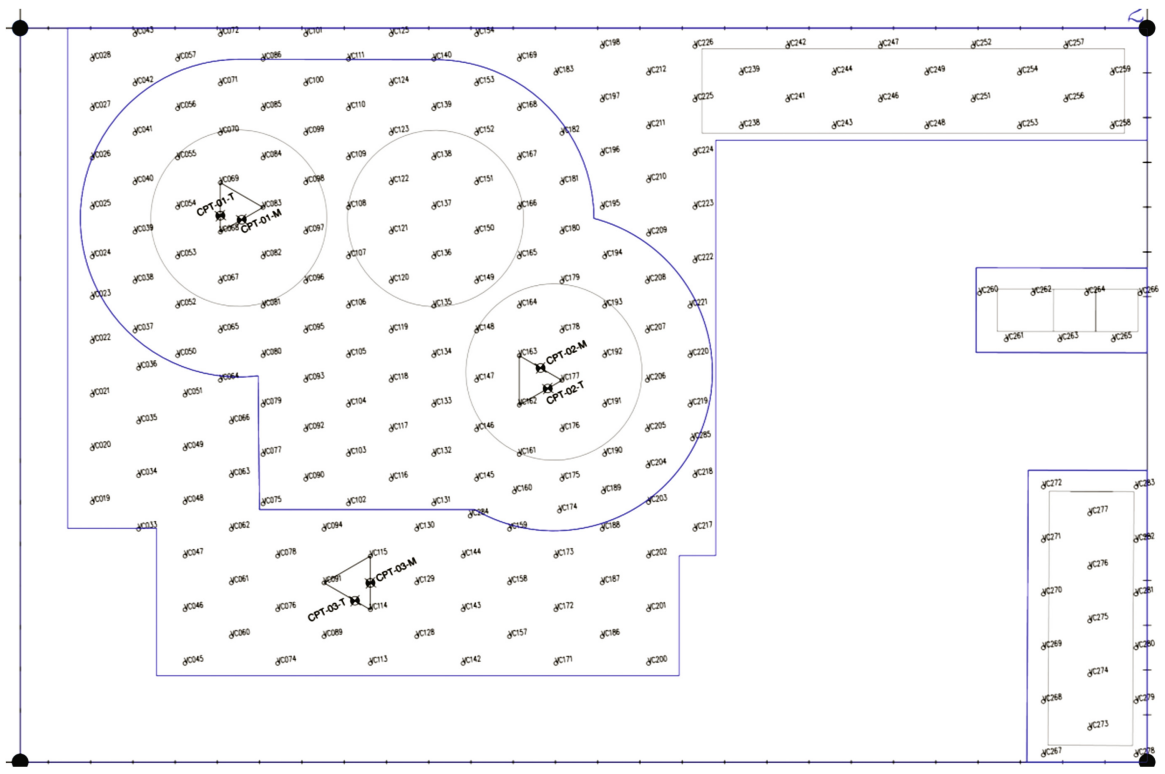

Fig. 8. Layout of VC points \& post-compaction CPT tests locations - Duqm site

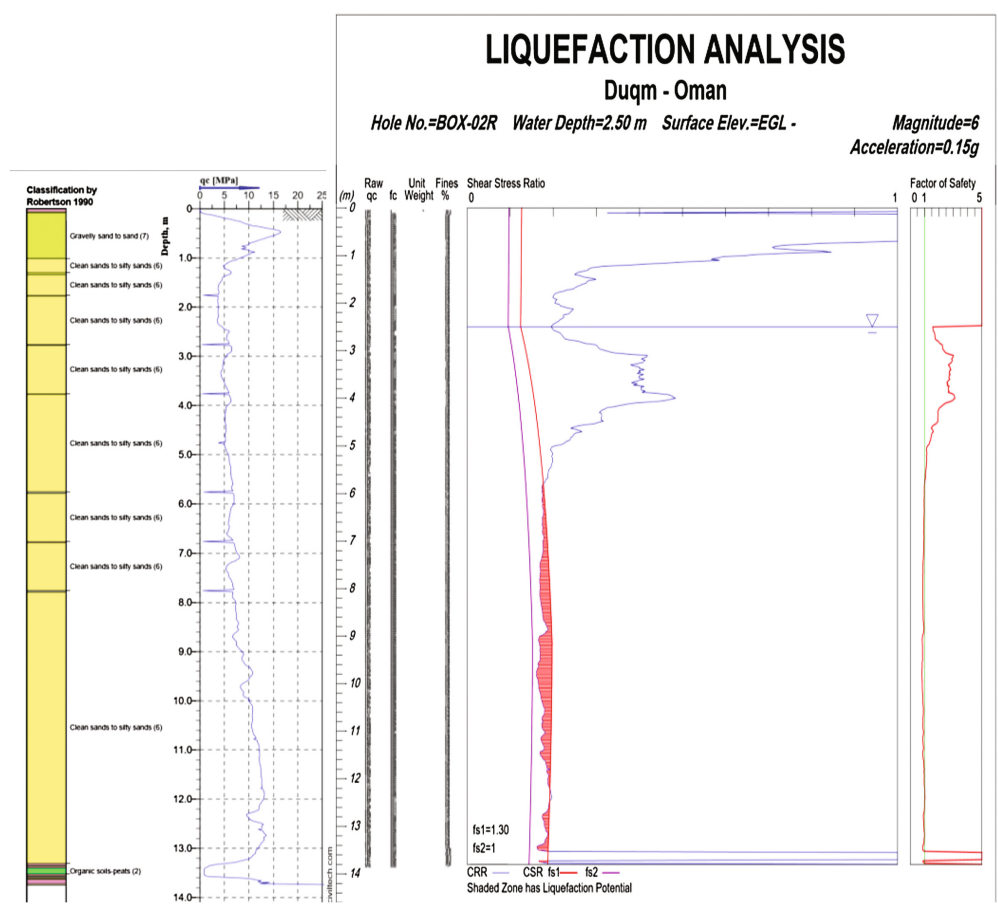

Fig. 9. Typical post-compaction- CPT result \& liquefaction analysis Duqm site 
Note: Liquefaction analysis is conducted according to NCEER (1997) recommendations with specialist software, which is commonly specified in most similar projects in GCC areas (e.g. Dubai). Design Earthquake effects as Magnitude (M) and Maximum ground acceleration $\left(\mathrm{a}_{\max }\right)$ ranges of 5.5-6 and 0.10-0.15 g, respectively were considered as adopted by the Geotechnical Investigation Study, with amplification factor of 1.5 applied through the reclaimed soil above rock level.

Later, 3 post-compaction DMT tests were conducted, each at the centre of the test areas of post-compaction CPTs, to assess $\mathrm{K}_{\mathrm{D}}$ effects on the CPT-Based liquefaction potential, and also for settlement performance of circular raft foundations proposed for the cement silos. Typical DMT results are shown in Fig. 10. Definitions of parameters measured and interpreted by DMT test are given in "Report of the ISSMGE, Technical Committee 16, 2001". The obtained results were repeatable and reliable.

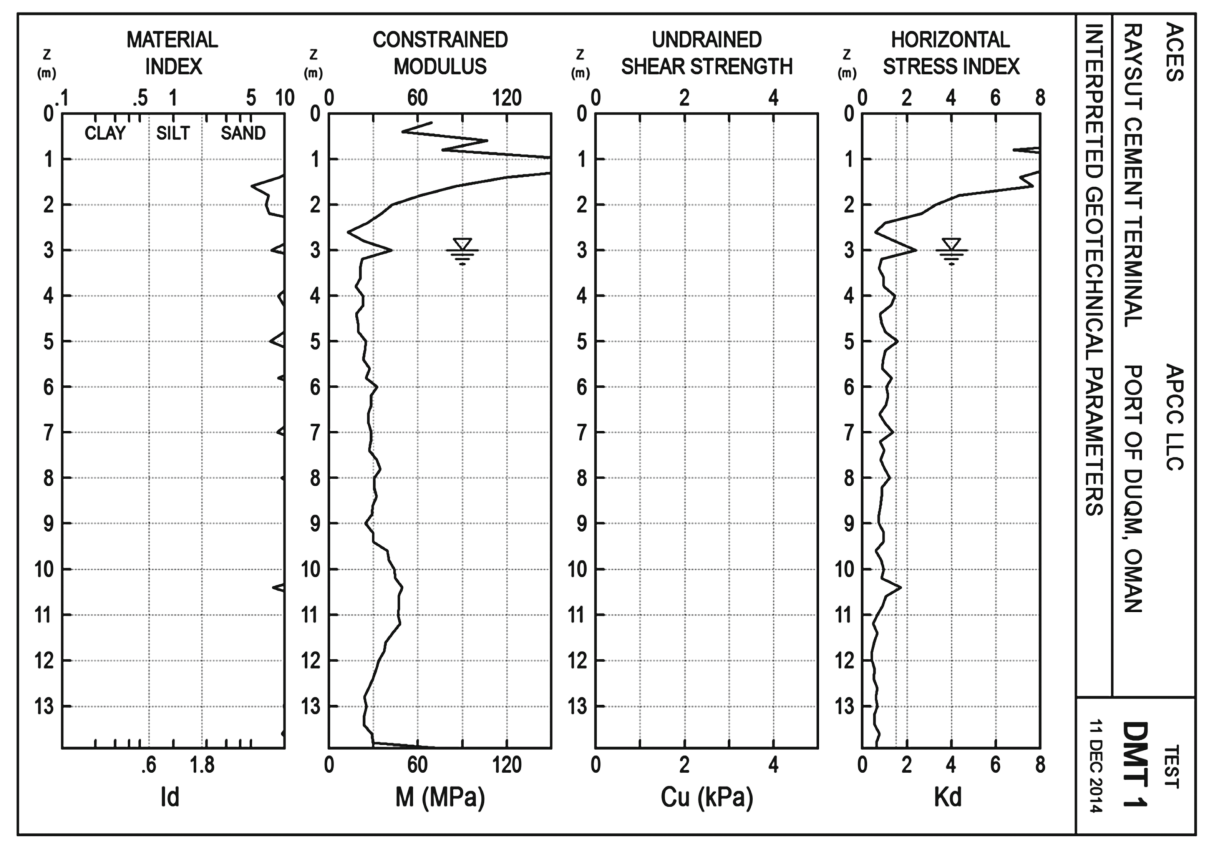

Fig. 10. Post-compaction Compaction DMT 1 (typical result) - Duqm site

Definitions of the different parameters incorporated with DMT test are shown in the below table extracted from The Flat Dilatometer Test (DMT) in Soil Investigation, Report of the ISSMGE, Technical Committee 16 on "Ground Property Characterization from In-Situ Testing”, 2001. 


\begin{tabular}{|c|c|c|c|c|}
\hline SYMBOL & DESCRIPTION & \multicolumn{3}{|c|}{ BASIC DMT REDUCTION FORMULAE } \\
\hline$p_{0}$ & Corrected First Reading & \multirow{2}{*}{\multicolumn{2}{|c|}{$\begin{array}{l}p_{0}=1.05\left(A-Z_{M}+\Delta A\right)-0.05\left(B-Z_{M}-\Delta B\right) \\
p_{1}=B-Z_{M}-\Delta B\end{array}$}} & \multirow{2}{*}{$\begin{array}{l}Z_{M}=\text { Gage reading when vented to atm. } \\
\text { If } \Delta A \& \Delta B \text { are measured with the same } \\
\text { gage used for current readings } A \& B \text {, } \\
\text { set } Z_{M}=0 \text { ( } Z \text { is compensated) }\end{array}$} \\
\hline $\mathbf{p}_{1}$ & Corrected Second Reading & & & \\
\hline$I_{D}$ & Material Index & \multicolumn{2}{|c|}{$\mathrm{ID}=\left(\mathrm{p}_{1}-\mathrm{p}_{0}\right) /\left(\mathrm{p}_{0}-\mathrm{u}_{0}\right)$} & $\mathrm{u}_{0}=$ pre-insertion pore pressure \\
\hline $\mathbf{K}_{\mathrm{D}}$ & Horizontal Stress Index & \multicolumn{2}{|c|}{$\mathrm{K}_{\mathrm{D}}=\left(\mathrm{p}_{0}-\mathrm{u}_{0}\right) / \sigma^{\prime} \mathrm{v}_{0}$} & $\sigma^{\prime} v_{0}=$ pre-insertion overburden stress \\
\hline$E_{D}$ & Dilatometer Modulus & \multicolumn{2}{|c|}{$\mathrm{ED}_{\mathrm{D}}=34.7\left(\mathrm{p}_{1}-\mathrm{p}_{0}\right)$} & $\begin{array}{l}\text { ED is NOT a Young's modulus } \mathrm{E} \text {. ED } \\
\text { should be used only AFTER combining it } \\
\text { with } \mathrm{KD} \text { (Stress History). First obtain } \\
\text { MDMT }=\mathrm{RM} \mathrm{ED}_{\mathrm{D}} \text { then } \mathrm{e.g} \text {. } \mathrm{E} \approx 0.8 \text { MDMT }\end{array}$ \\
\hline $\mathbf{K}_{0}$ & Coeff. Earth Pressure in Situ & \multicolumn{2}{|c|}{$\mathrm{K}_{0, \mathrm{DMT}}=\left(\mathrm{K}_{\mathrm{D}} / 1.5\right)^{0.47}-0.6$} & for $I_{0}<1.2$ \\
\hline OCR & Overconsolidation Ratio & \multicolumn{2}{|c|}{ OCRDMT $=(0.5 \mathrm{KD})^{1.56}$} & for $I_{D}<1.2$ \\
\hline$c_{u}$ & Undrained Shear Strength & \multicolumn{2}{|c|}{$\mathrm{Cu}, \mathrm{DMT}=0.22 \sigma^{\prime} \mathrm{v} 0(0.5 \mathrm{KD})^{1.25}$} & for $I_{D}<1.2$ \\
\hline$\Phi$ & Friction Angle & \multicolumn{2}{|c|}{$\Phi_{\text {safe, DMT }}=28^{\circ}+14.6^{\circ} \log \mathrm{KD}_{\mathrm{D}}-2.1^{\circ} \log ^{2} \mathrm{KD}$} & for $I_{D}>1.8$ \\
\hline$c_{h}$ & Coefficient of Consolidation & \multicolumn{2}{|c|}{ Ch,DMTA $\approx 7 \mathrm{~cm}^{2} /$ tflex } & tfiex from A-log t DMT-A decay curve \\
\hline $\mathbf{k}_{\mathrm{h}}$ & Coefficient of Permeability & \multicolumn{2}{|c|}{$\mathrm{kh}_{\mathrm{h}}=\mathrm{Ch} \gamma_{\mathrm{w}} / \mathrm{Mh}_{\mathrm{h}}\left(\mathrm{Mh}_{\mathrm{h}} \approx \mathrm{K}_{0}\right.$ МомT $)$} & \\
\hline$\gamma$ & Unit Weight and Description & \multicolumn{2}{|c|}{ (see chart in Fig. 16) } & \\
\hline M & $\begin{array}{l}\text { Vertical Drained Constrained } \\
\text { Modulus }\end{array}$ & \multicolumn{2}{|c|}{ 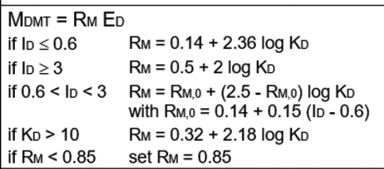 } & \\
\hline $\mathbf{u}_{0}$ & Equilibrium Pore Pressure & \multicolumn{2}{|c|}{$\mathrm{u}_{0}=\mathrm{p}_{2}=\mathrm{C}-\mathrm{ZM}+\Delta \mathrm{A}$} & In free-draining soils \\
\hline
\end{tabular}

\section{Incorporating DMT Results to Support CPT-Based Liquefaction Analysis}

In his recent paper, Marchetti (2016) described a method to incorporate the stress history parameter $\left(K_{D}\right)$ of DMT into the Liquefaction Correlations. The final recommended relationship that shows the new correlation is shown in Fig. 11.

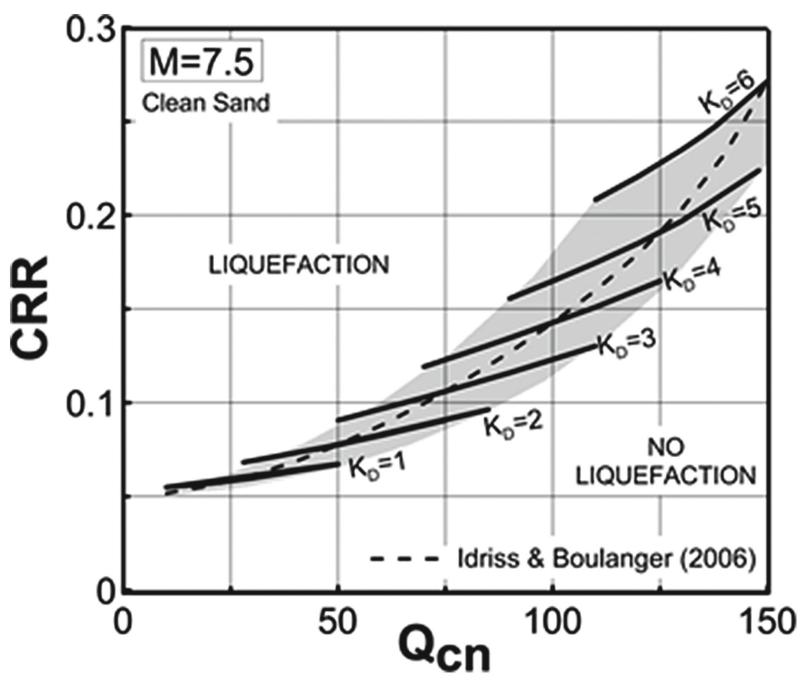

Fig. 11. Chart for estimating CRR in clean sand based on $Q_{c n} \& K_{D}$ (Marchetti 2016) 
The relationship is based on $Q_{c n}, K_{D}$ relationship as $Q_{c n}=25 \times K_{D}$ given earlier by Robertson (2012), therefore, CRR is evaluated from measured CPT $\left(Q_{c n}\right)$ and also from $Q_{c n}=25 \times K_{D}$, and the average CRR is then evaluated as: Average CRR = $\left[\left(\mathrm{CRR} \text { from } Q_{c n}\right) \times\left(\mathrm{CRR} \text { from } K_{D}\right)\right]^{0.5}$. CRR is the cyclic soil resistance. The CRR values provided by Fig. 11 can be regarded as the sum of two parts. One part, the bulk of it, is the CRR estimated by the CPT consensus curve. The other part is the $K_{D}$ correction. An advantage of Fig. 11 is that it shows in one graph the whole picture, facilitating the recognition of trends. For instance the graph indicates that for high values of $K_{D}$ and $Q_{c n}$, corresponding to seasoned sands, the differences between the curves are higher. This later observation is of importance as the likely improvement effect of $K_{D}$ on the value of soil cyclic resistance CRR can be quickly noticed. Therefore, for low $K_{D}$ of $<2$, the effects may be ignored, whereas for higher $K_{D}$, then the effects are regarded as significant. This is also illustrated in Fig. 12 as given by Marchetti (2015).

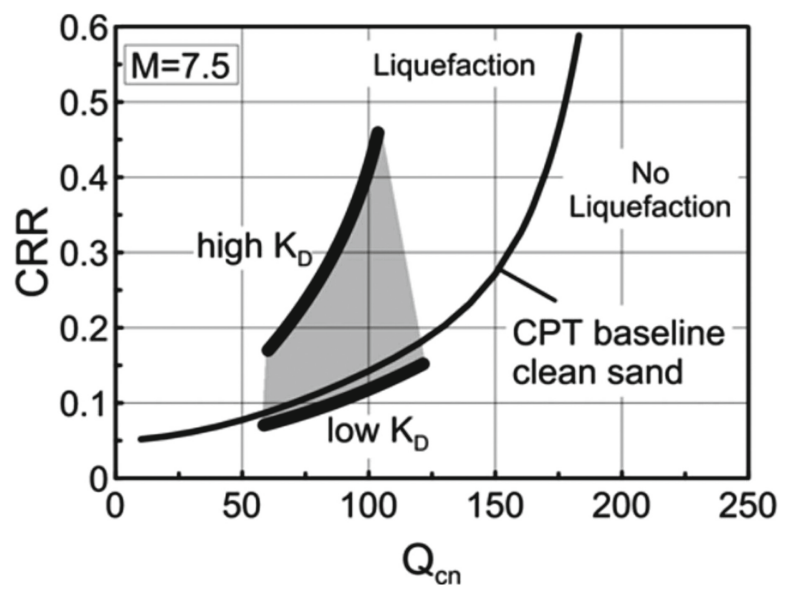

Fig. 12. CRR expressed as a function of $Q_{c n} \& K_{D}$. Qualitative framework (Marchetti 2015)

An excel sheet was prepared to conduct the analysis for the above. The 3 DMT tests conducted in the middle of each test triangle has indicated low KD as indicated in the above tests results (from slightly $<1$ to 1 for tests $1 \& 3$ and around 2 to 3 for test 2). The conclusion was that $\mathrm{K}_{\mathrm{D}}$ results did not impose any improvement on CRR, and the site was still classified as liquefiable and further round of VC was specified. The DMT results, however has also indicated the spatial variation as indicated by different ranges of $\mathrm{K}_{\mathrm{D}}$, which is in close agreement with the post-compaction CPT findings.

Following re-compaction works conducted by the contractor, other round of post-compaction CPT tests were only conducted that indicated satisfactory performance, as illustrated in Fig. 13. $2^{\text {nd }}$ round of VC - Typical Post-compaction CPT result:

Liquefaction analysis was found satisfactory and the site was accepted, and the construction commenced. 


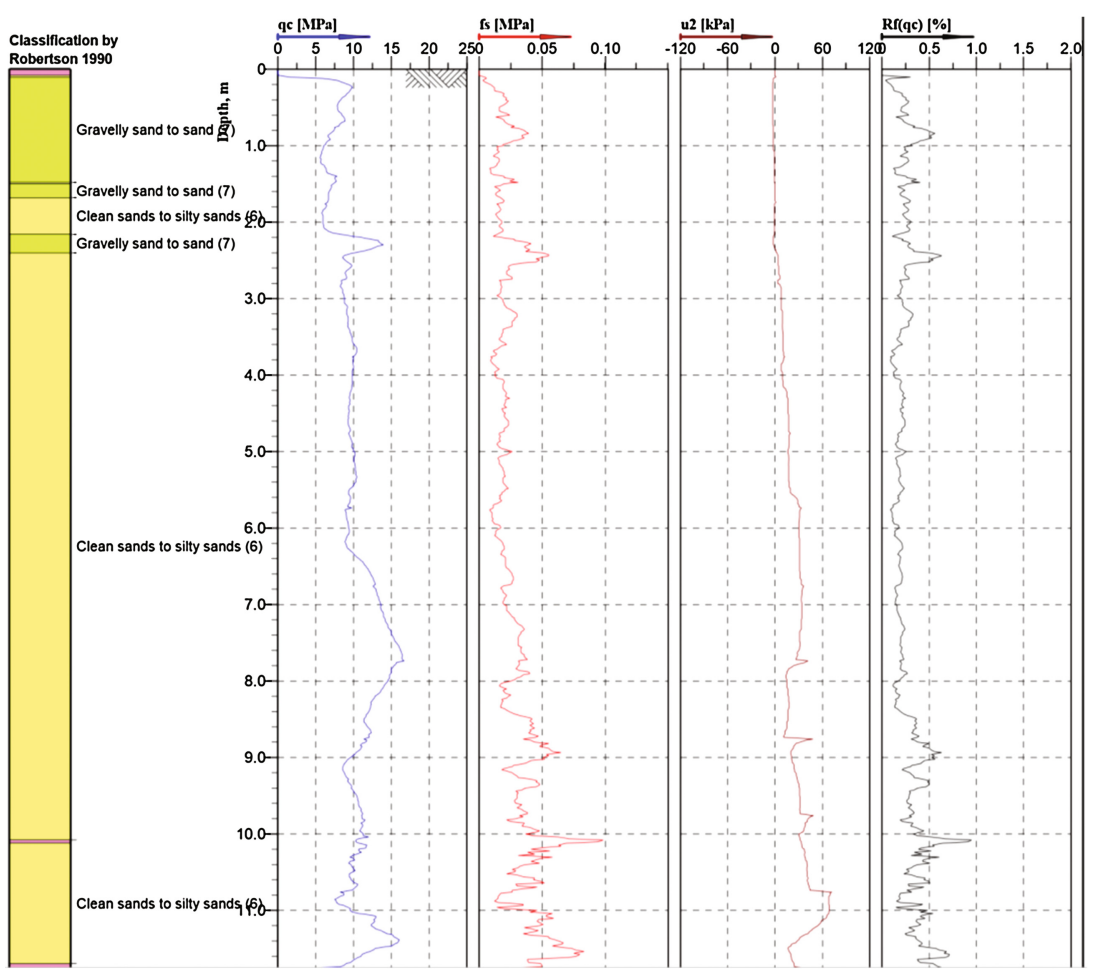

Fig. 13. Typical post-compaction compaction ( $2^{\text {nd }}$ round) CPT - Duqm site.

\subsection{Case 2: Confirming OC Nature of Previously Vibro-Compacted, Aged Sandy Fill in PJ in Dubai}

Dubai is part of United Arab Emirates. It lies on the Arabian Gulf as shown in Fig. 14. Dubai area is distributed physiographically into main land and coastal areas in a ratio of $9: 1$. The main land is mostly occupied by Aeolian/desert sand dunes ( $80 \%$ of the area) with hard encrustations of local/in land sabkha's in areas with near surface water table and thin sheets of Aeolian sand overlying the local fans of gravels. The sand dune near coastal belt is enriched with carbonate source material from the sea-shells and carbonate rocks.

Dubai is Famous of its tall towers and several man made islands as indicated in Fig. 15.

Subsurface geological and geotechnical conditions in the island are described as follows. Results of Typical Test Borings in the Island would show the typical profile as illustrated in Fig. 16, composed of:

An upper layer of man hydraulically laid sandy fill of $12-18 \mathrm{~m}$ in depth sitting on a thin, weak sea bed layer of very silty SAND to sandy SILT (Carbonate content exceeds $70 \%$ and is $>90 \%$ for many samples), followed by Cap rock of Calcarenite and Sandstones. 

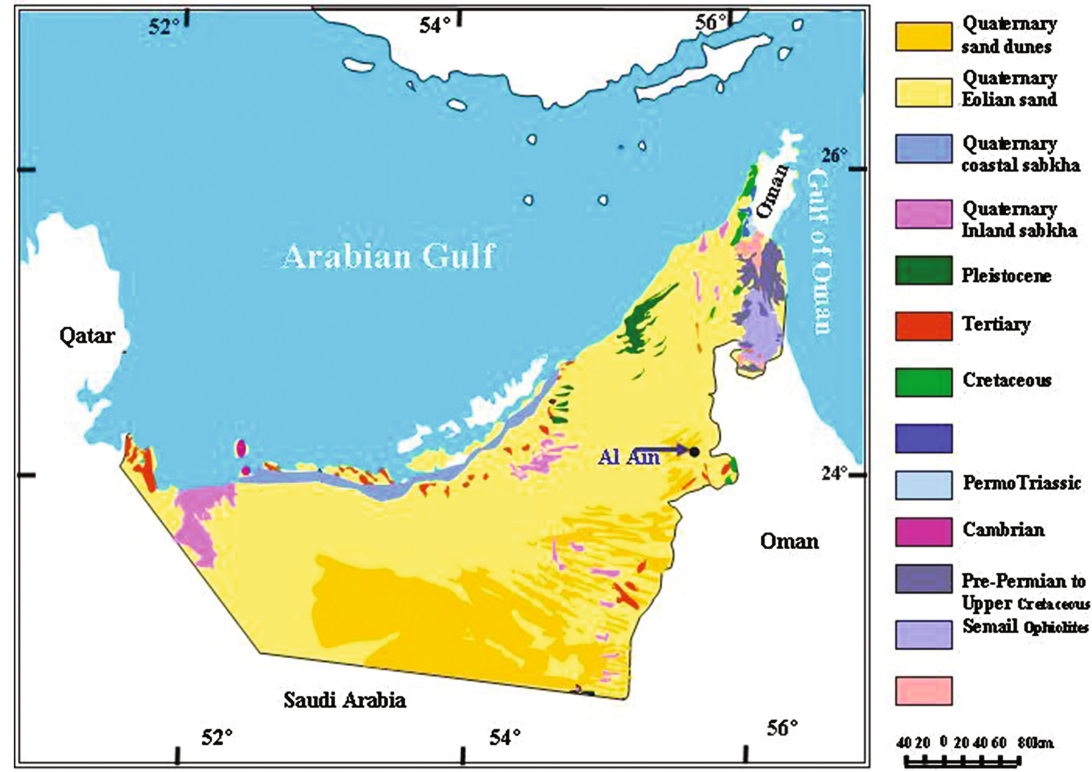

Fig. 14. Map of UAE indicating Dubai on the map

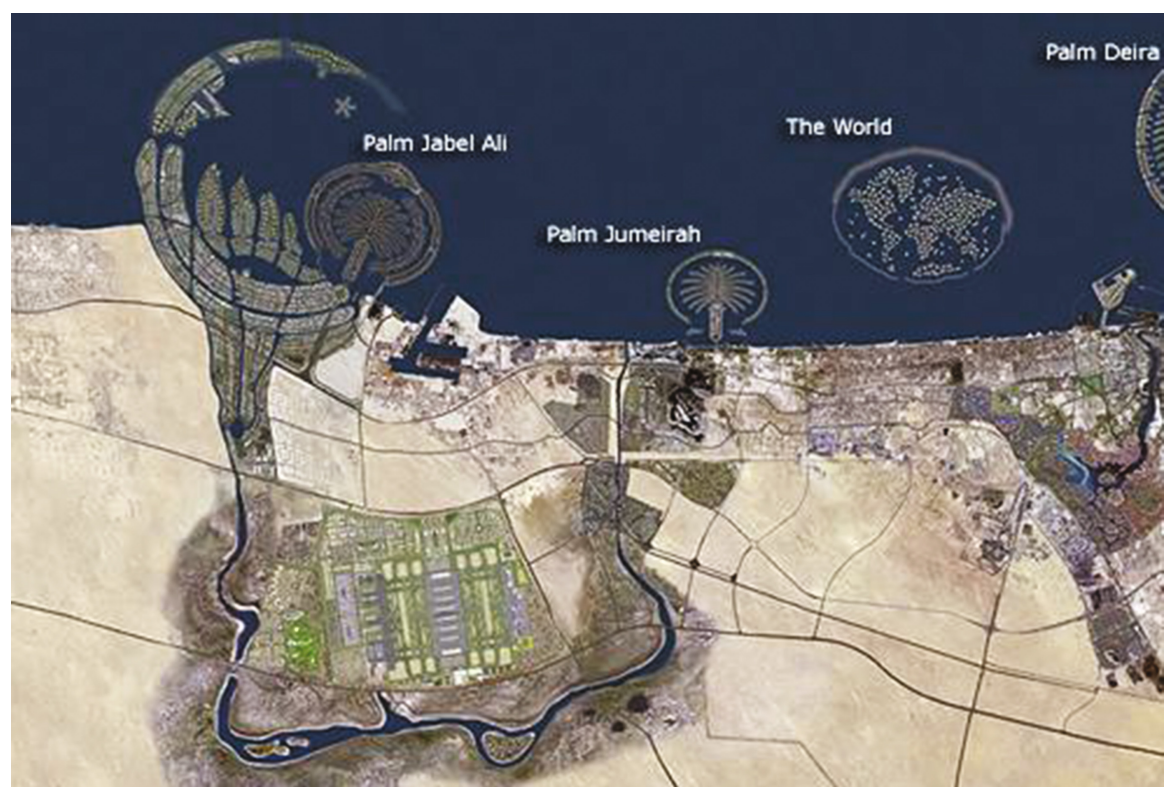

Fig. 15. Sattelite image of Dubai and coast line 


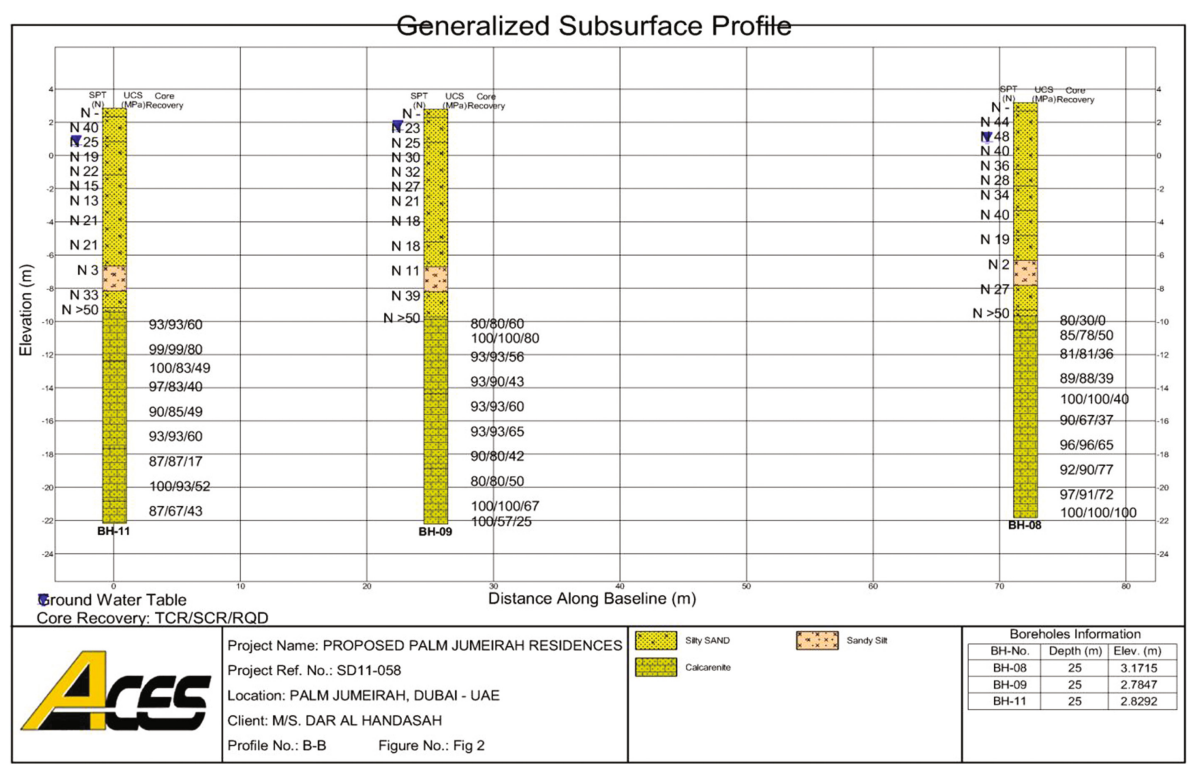

Fig. 16. Typical subsurface conditions within PJ Island

\subsubsection{Application of DMT in Palm Jumeira}

The site of a prestigious new project lies on the crescent Palm Jumeira. The site area is $>150,000$ sq. $\mathrm{m}$ with 4 towers of 160-190 m height range. The architectural design of the project as schematically indicated in Fig. 17, will make it a new landmark in Dubai.

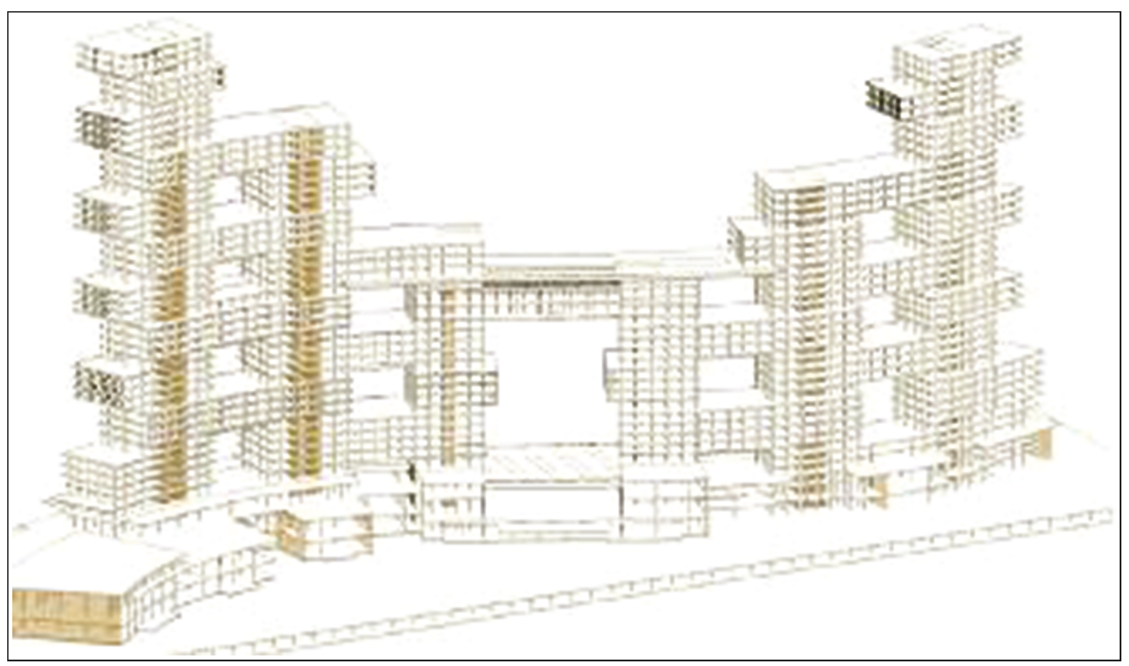

Fig. 17. View of the project architecture 
The subsurface ground conditions are typical of the Palm Jumeira in general as indicated in the generalized subsurface profile presented in Fig. 18.

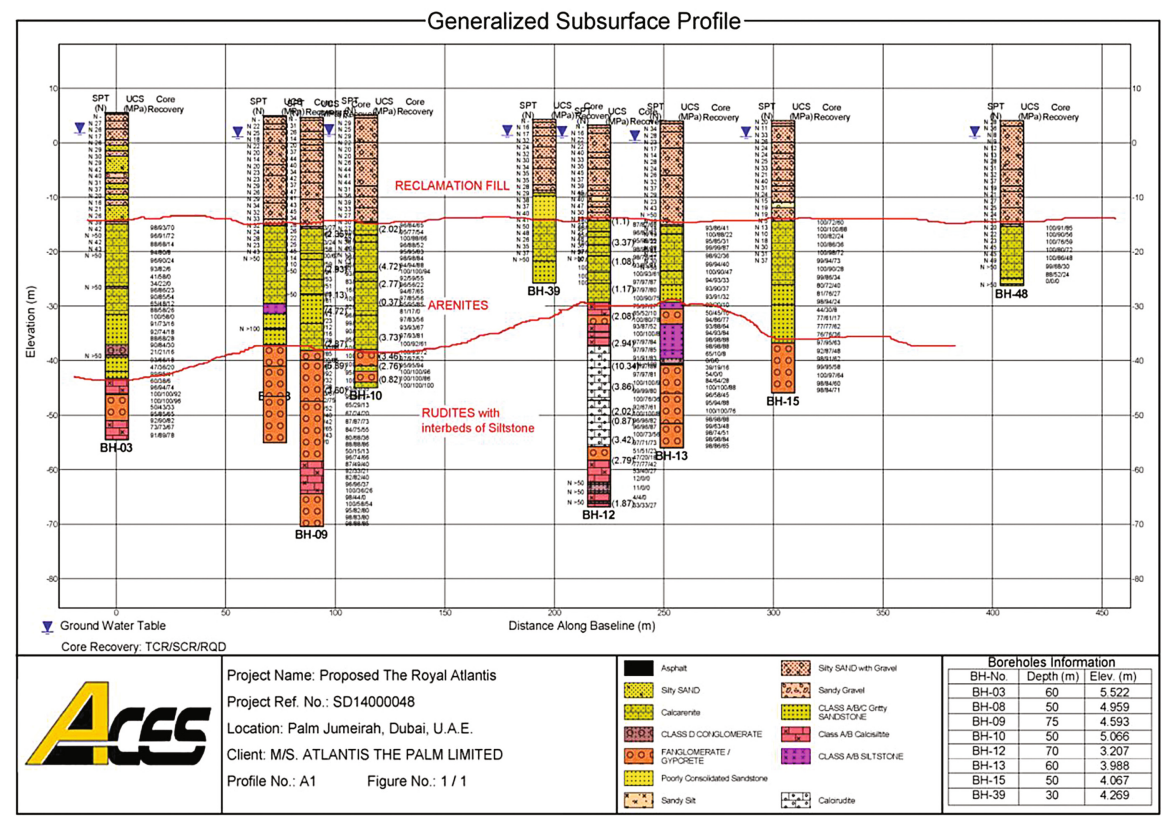

Fig. 18. Generalized subsurface profile along the site - Palm Jumeira Dubai

The upper silty SAND earthfill was previously deep compacted with Vibro Compaction since more than 8 years and hence the CPT tests results indicated dense conditions. Seismic studies included in-situ tests conducted to measure the shear wave and other dynamic properties of the site.

The typical MASW (multi-channel analysis of surface waves) results in the vicinity of the above CPT test result as shown in Fig. 19, indicate the shear wave velocity of the upper sand generally exceeds 400 to $500 \mathrm{~m} / \mathrm{s}$ particularly within the upper $10 \mathrm{~m}$.

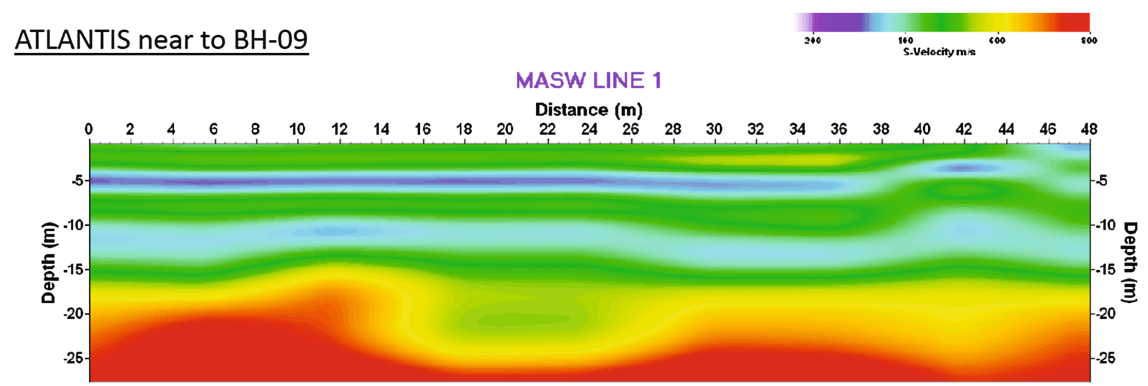

Fig. 19. Typical MASW profile - PJ Dubai 
This was explained to be a result of the over-consolidated nature of the soil due to aging effects as reflected by the relatively high CPT results. However, a more specific justification was required to address the OCR which is difficult to assess by CPT tests results for sandy soil. Accordingly, few DMT tests were conducted at selected locations to establish the constrained modulus (M) profile and establish the DMT (M)/CPT (qc) ratio that would indicate the $\mathrm{OC}$ nature of the sand. Figure 20 presents the result of typical DMT (M) and CPT (qc) in Mpa as obtained.

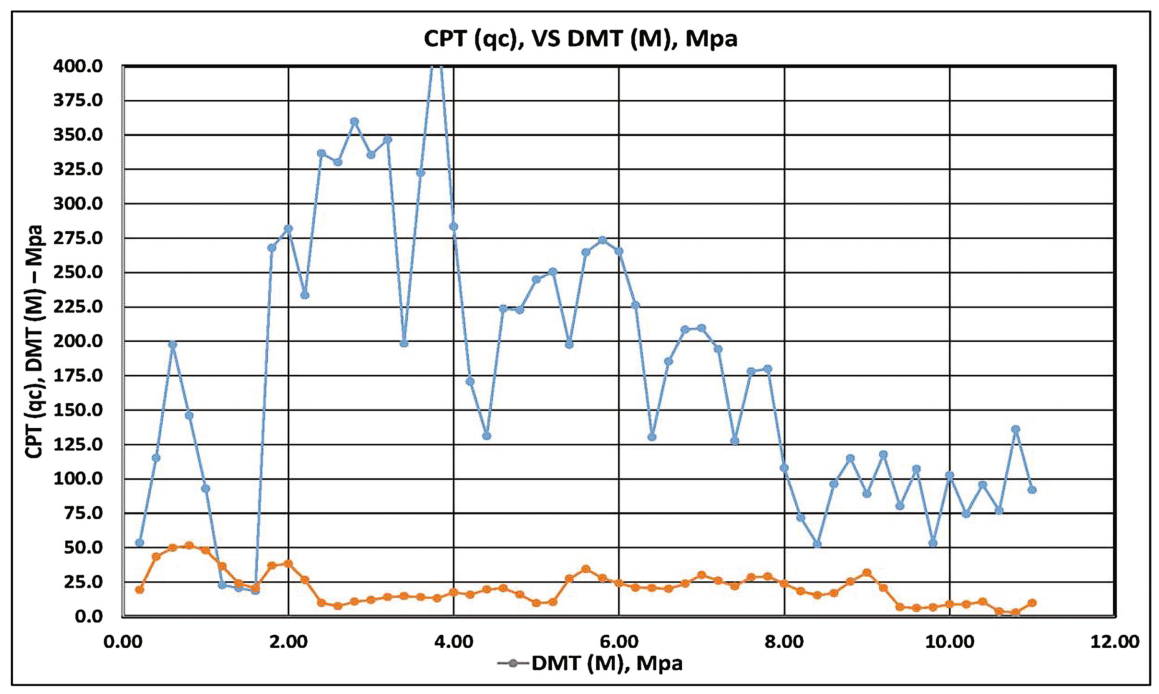

Fig. 20. DMT (M) - blue curve - and CPT (qc) - red curve - in Mpa vs. Depth

The $\mathrm{M} / \mathrm{qc}$ ratio is presented in the below graph and the $1 \mathrm{~m}$ rolling average is also indicated.

$\mathrm{M} / \mathrm{qc}$ ratio indicated in Fig. 21 shows that it is greater than 8 for the upper $8 \mathrm{~m}$ and exceeding 25 within the upper OC crust. This is a clear confirmation of the OC nature of the earthfill and provides the necessary justification of the MASW results. It further provided general good matching with CPT and MASW results.

\subsection{Case 3: Accurate Settlement Prediction of Large Diameter Oil Storage Tanks}

DMT was used in a Tank Farm Project in the Port of Al-Fujeira in UAE for accurate assessment of the proposed large diameter tanks settlement. The oil storage tanks are typically constructed within the ports close to coastal lines where relatively poor soil conditions exist. Therefore, accurate assessment of foundation settlement is very important to decide if ground improvement is required or not. The settlement estimates depend on the assessed soil modulus (E) or constrained modulus (M). For silty sandy soils that are generally encountered in that area, the estimates are generally based on 


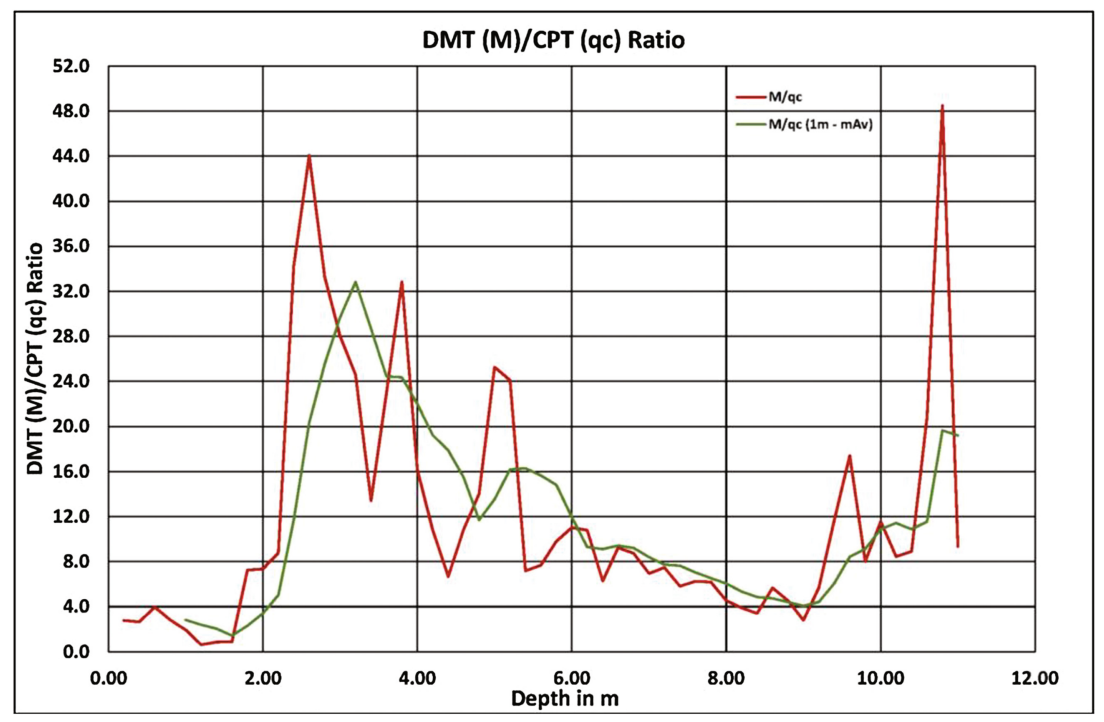

Fig. 21. M/qc ratio vs. depth

SPT and CPT (qc - tip resistance) tests results, which would generally result in low range values of $\mathrm{E}$. The most commonly used relations are:

$$
\begin{aligned}
& \mathrm{E}=\mathrm{N}_{60}(\mathrm{Mpa})-(\text { Ciria Report } 43,1995) \\
& \mathrm{M}=4 \mathrm{qc} \text { for }(\mathrm{qc}<10 \mathrm{MPa}) \\
& \mathrm{M}=2 \mathrm{qc}+20 \mathrm{Mpa} \text { for }(10<\mathrm{qc}<50 \mathrm{MPa}) \\
& \mathrm{M}=120 \mathrm{Mpa} \text { for }(\mathrm{qc}>50 \mathrm{MPa})-(\text { Lunne et al. } 1997)
\end{aligned}
$$

The Eurocode 7 , mentions $(\mathrm{E}=2.5 \mathrm{qc} \mathrm{MPa})$, which is also consistent with the above estimate of $\mathrm{M}$ for $\mathrm{NC}$ conditions of sand. For OC sands, the following relation is typically recommended: $\mathrm{M}=5 \mathrm{qc}$ for $(\mathrm{qc}<50 \mathrm{MPa}$ ), and $\mathrm{M}=250 \mathrm{MPa}$ for ( $\mathrm{qc}>$ $50 \mathrm{MPa}$ ) (Lunne et al. 1997).

The relation between M, Shear Modulus G and Young's Modulus E according to Elasticity Theory, based on Poisson's ratio $v$ are given below:

$$
\mathrm{M} / \mathrm{G}=2(1-v) /(1-2 v), \text { and } \mathrm{G} / \mathrm{E}=2(1+v)
$$

The effect of over consolidation (stress history) is a main factor that is generally underestimated with CPT based M or E estimates.

\subsubsection{Effect of Shear Strain/Loading Level}

The foundation settlements shall be assessed for shear strain in the range of $0.1 \%$ (This is established based on observations made for well designed actual foundations). Therefore, with absence of reliable procedure to estimate OCR of sands from the results of CPT or SPT tests, then, the above is only illustration of the amount of conservatism or risk which the interpreter has to take to estimate $\mathrm{M}$ or $\mathrm{E}$ for his calculations! 
For large diameter tanks $(>50 \mathrm{~m})$, the use of conservative estimates of Es would result in settlements exceeding the maximum permissible limit (API 650) and hence deep ground improvement and other expensive solutions would be needed. Figure 22 shows illustration of the sensitivity of settlement of the tank to the modulus $E$ of the upper overburden soil layer.

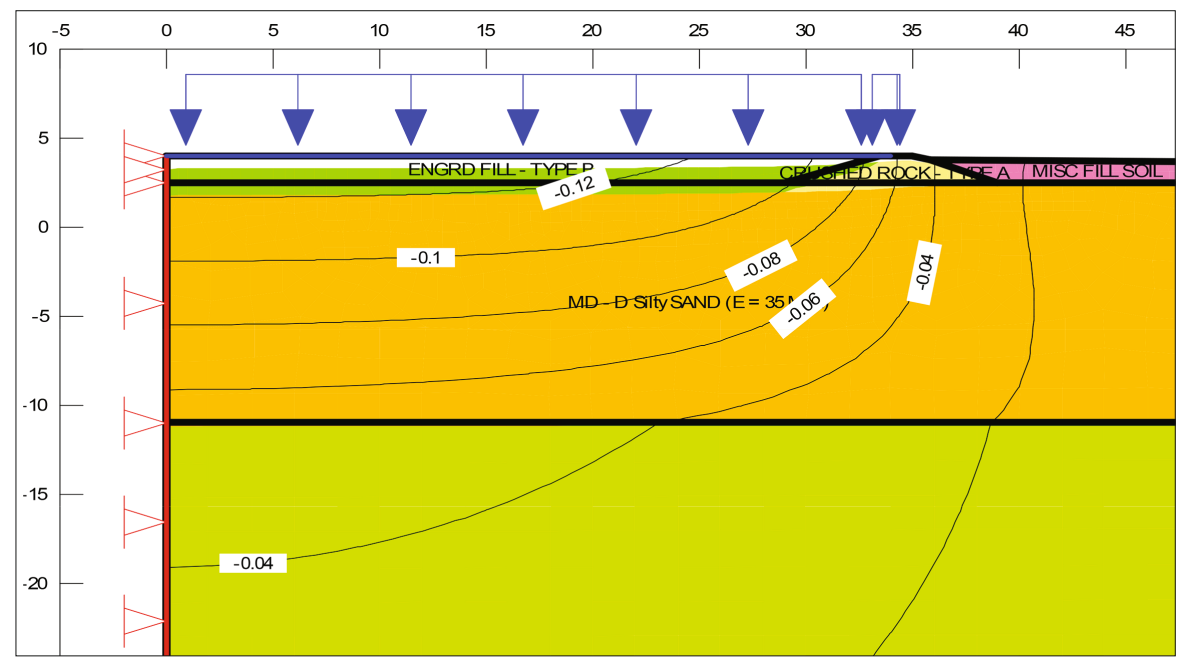

Fig. 22. $\mathrm{E}=35 \mathrm{Mpa}-$ settlement at tank edge $=60 \mathrm{~mm}$

Typical settlement analysis of $68 \mathrm{~m}$ Diameter tank for range of $\mathrm{E}$ modulus of the upper overburden silty Sand for $300 \mathrm{kPa}$ uniform Hydrotest pressure.

By adopting DMT based modulus of $60 \mathrm{Mpa}$, then the edge settlement was found to be $45 \mathrm{~mm}$ only.

Note: Axi-Symmetric FE analysis for settlement was conducted with Sigma/W software (www.geo-slope.com).

Local experience has indicated that actual tank settlements under hydrotest loading test are much less than the theoretical estimates of tank settlements based on the above SPT and CPT methods. The actual measured settlements are typically $<50 \%$ of the theoretical estimates.

The cost of deep ground improvement with Vibro-Compaction or Stone Columns is several hundred thousands of dollars per each large diameter tank, in addition to several months of delay of the project.

It is also important to point out that the hydrotest conducted (API 650) at the completion of construction of each tank is a preload that causes most of the permanent settlement component to take place and subsequent unloading and reloading of the tank during its operational life time would follow the more stiff reloading/unloading modulus with in-significant movements as experienced with so many existing tanks of various diameters. 
Therefore, the accurate and reliable assessment of the soil modulus is very significant for confidence of the estimated foundation settlement. DMT was therefore introduced to provide reliable and direct measurement of in-situ modulus of the soil and provide site - specific correlation to the other penetration tests as SPT and mostly CPT that are widely used.

Case Study: The proposed storage tank farm includes tanks having diameters of $68 \mathrm{~m}$ and $36 \mathrm{~m}$ for the small ones. All the tanks were designed for an average max. hydrotest load of up to $300 \mathrm{kPa}$. The main design criteria is that the shell plate settlement under max. load not to exceed $50 \mathrm{~mm}$ (preferable). However, settlements up to $100 \mathrm{~mm}$ may be tolerated by the owner, provided the settlements are uniform (differential settlements between edge points at $10 \mathrm{~m}$ arc length not to exceed $13 \mathrm{~mm}$ ) and most of the settlements to be of short term nature (to take place during the hydrotest).

The investigation for this Tank farm project consisted of a number of geotechnical boreholes drilled up to $40 \mathrm{~m}$ depth, CPT and DMT tests in addition to geophysical survey with MASW (Multi Channel Analysis of Surface Waves), as given in Fig. 23.

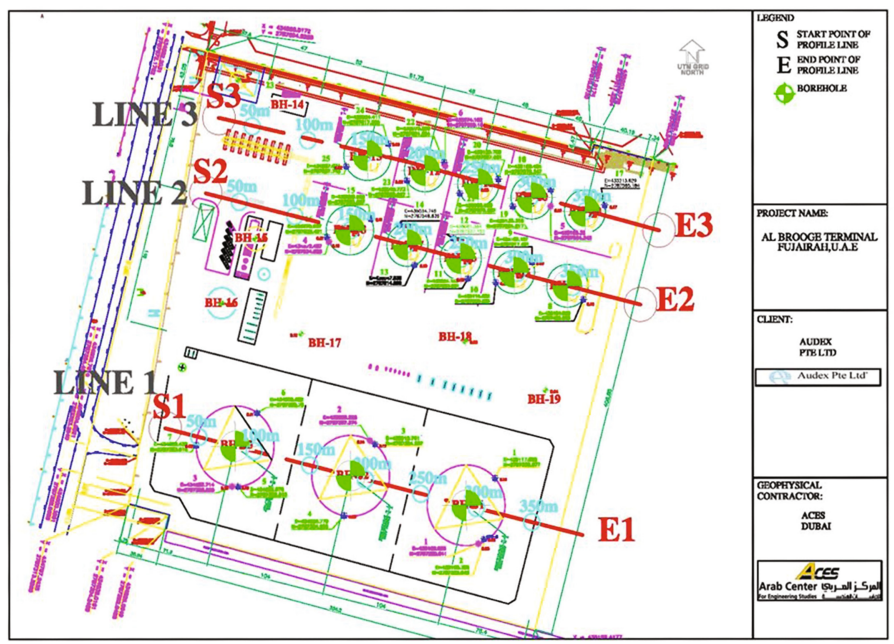

Fig. 23. Layout of 3 MASW lines covering all tanks locations

The typical geological cross section indicated the site is made up of thin upper rockfill layer of 1-4 m thickness that was constructed to provide a level platform with thickness increasing towards the sea side, underlain by medium dense to dense fine silty sand that is followed by bedrock of very weak to weak Sandstone and conglomerates. GWT exists at $2.5 \mathrm{~m}$ depth approximately. Generalized subsurface profile showing the main soil and rock layers is shown in Fig. 24. SPT results of all boreholes indicated Medium dense to Dense soil with few localized weak lenses/pockets. The DMT \& CPT results, after $3 \mathrm{~m}$ of pre-drilling though rockfill cover, indicated OC sand followed by Medium dense silty Sand, as shown in Fig. 25. 


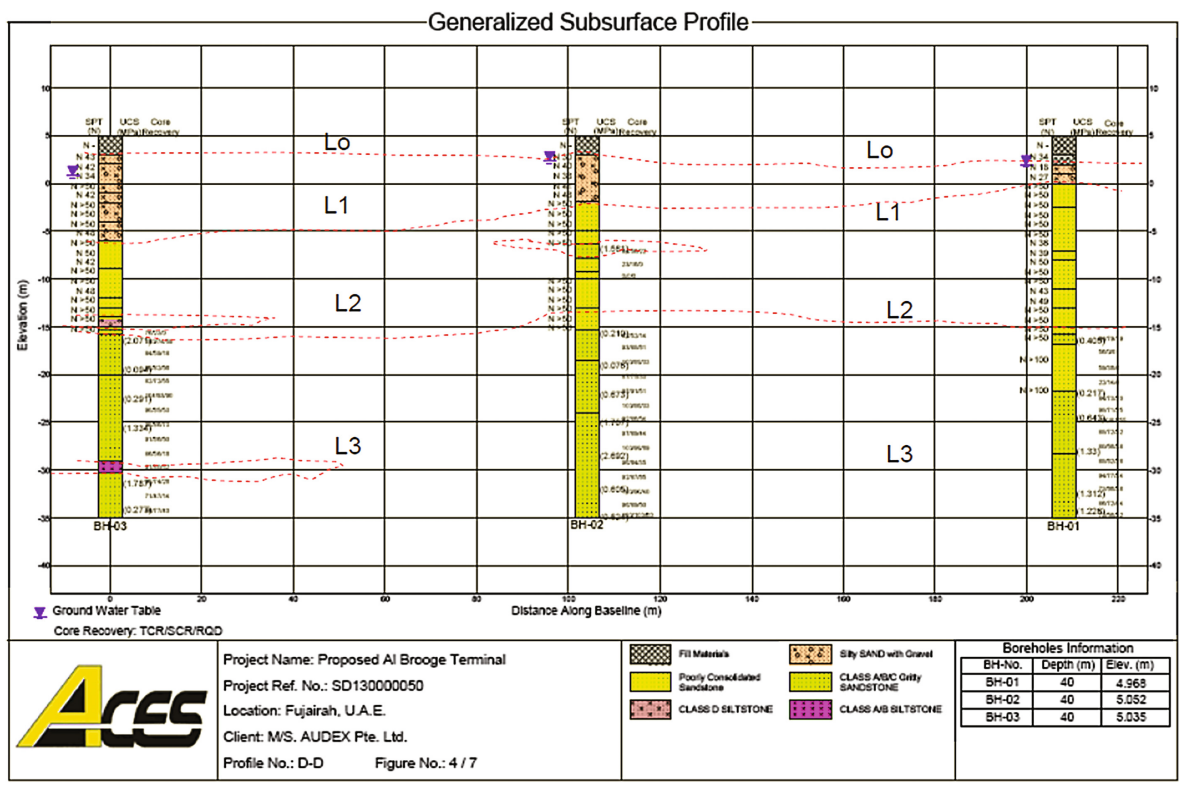

Fig. 24. Subsurface profile indicating general homogeneity - Fujeira site.

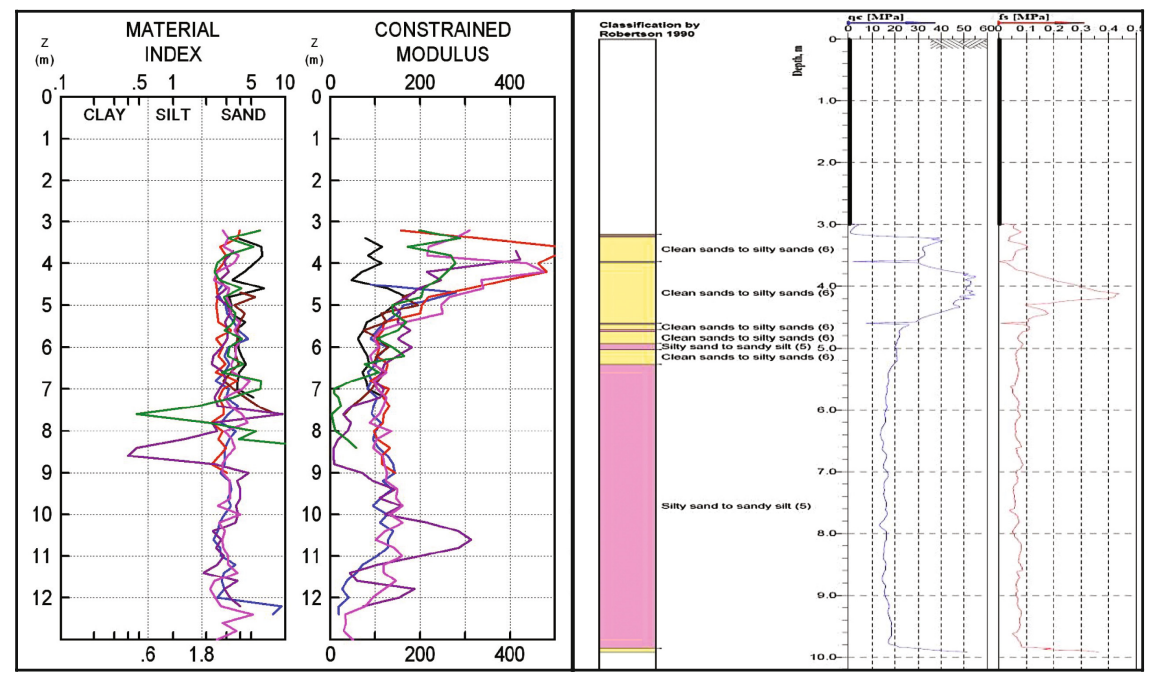

Fig. 25. Summary of all the 7 DMT tests \& typical CPT test result with SBT profiling

The main parameter controlling the settlement estimates of the sand is obviously the modulus of deformation E. Based on SPT and CPT results, the average Es was estimated to be 35-40 Mpa, resulting in settlements exceeding $50 \mathrm{~mm}$ at the large diameter tank edges. Based on direct measurement of DMT, M average was slightly 


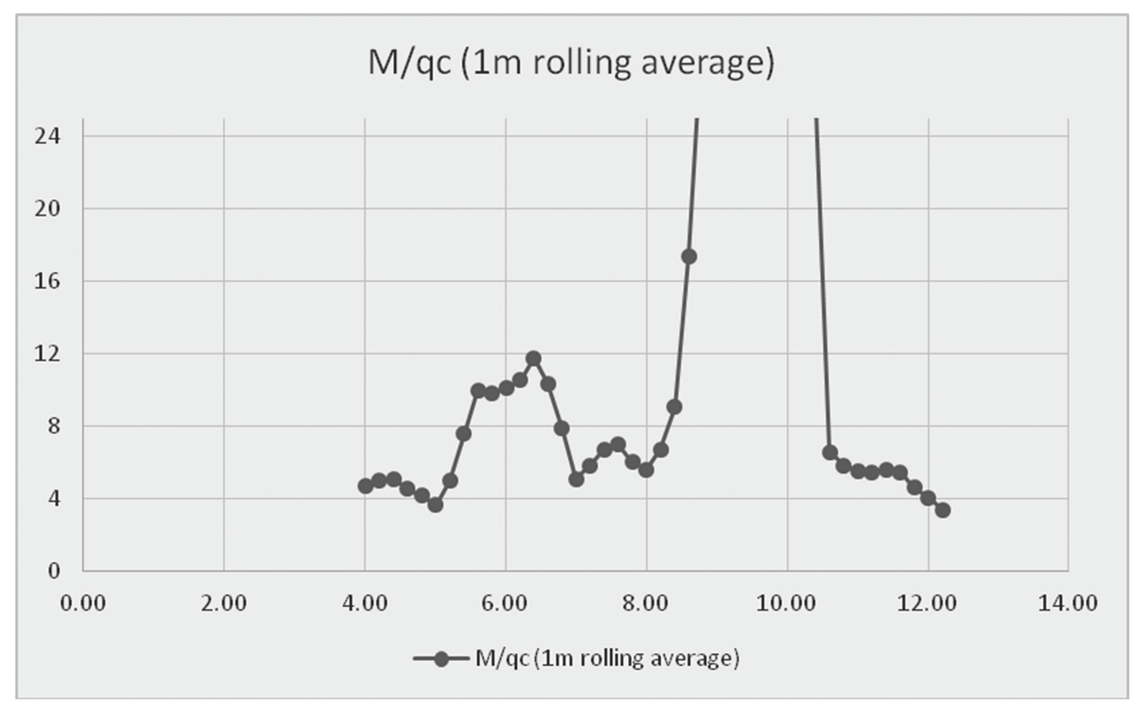

Fig. 26. $M / q c$ ratio obtained (vertical axis) vs. depth (horizontal axis) in $m$

around $100 \mathrm{Mpa}$, and $\mathrm{E}$ is $>60 \mathrm{Mpa}$. The typical DMT (M)/ CPT (qc) ratio is shown graphically in Fig. 26.

It shows that M/qc may safely be taken as 6 instead of 4 as adopted for NC sand, which means that for average qc $=15 \mathrm{Mpa}$, then $\mathrm{M}=90 \mathrm{Mpa}$ and $\mathrm{E}$ will be $>60 \mathrm{Mpa}$. This is at least $50 \%$ greater than the typical CPT based estimates adopting NC sand conditions.

The final recommendation suggested that no deep ground improvement is necessary for settlement limitation. Vibro Compaction was only suggested for the main tanks to improve the stiffness within potential weak localities, as indicated by the CPT and some of the DMT results. The project construction phase has commenced and the next step will be the observation of the results of actual hydrotests that are planned for each of the tanks, which will provide the final confirmation on the foundation ground behavior. As stated previously, previous experience has indicated that the actual results of settlements are less than the theoretical predictions. This will increase the confidence in the methods adopted for the soil modulus estimates.

\section{Conclusion}

The use of DMT in Dubai and the Arabian Gulf Area is relatively recent. The early applications presented in this paper indicate that DMT would be of great value to identify the effects of previous stress history and over-consolidation of either man made and stabilized embankments or natural sandy soils, resulting in better understanding of actual foundation soil behavior and avoiding expensive foundation solutions that may not be necessary. Further, the use of DMT to support the confidence on assessment of the liquefaction potential by CPT or SPT-Based methods is of main significance, 
particularly for aged sands which are vibro-compacted before some time. With future accumulated experience, a more rich data base would be established that would increase the level of confidence of the use of DMT for in-situ modulus estimates and to provide a site specific calibration to other commonly used penetration tests as CPT and SPT. The documentation of results of full scale hydrotests on large diameter storage tanks provides great opportunity for that purpose. Further, applications for design and quality control of deep ground improvement projects and liquefaction potential assessment form other wide area of future use of DMT in Dubai and the Gulf Area.

\section{References}

API 650: Welded Steel Tanks For Oil Storage, 11th edn., June 2007

Clayton C.R.I.: The Standard Penetration Test (SPT): methods and use. CIRIA Report 143, London (1995)

Marchetti, S.: Some 2015 updates to the TC16 DMT report 2001. In: Proceedings of 3rd International Conference on the Flat Dilatometer DMT 2015, Rome, Italy, pp. 43-65 (2015)

Marchetti, S.: Incorporating the stress history parameter $\mathrm{K}_{\mathrm{D}}$ of DMT into the liquefaction correlations in clean uncemented sands. J. Geotech. Geoenviron. Eng. 142(2), 04015072 (2016)

NCEER: Proceedings of the NCEER workshop on evaluation of liquefaction resistance of soils. Technical report NCEER-97-0022, 31 December 1997

Robertson, P.K.: Interpretation of cone penetration tests - a unified approach. Can. Geotech. J. 46 (11), 1337-1355 (2009). doi:10.1139/T09-065

Robertson, P.K.: The James K. Mitchell lecture: interpretation of in-situ tests - some insights. In: Proceedings of 4th International Conference on Geotechnical and Geophysical Site Characterization, Porto de Galinhas, vol. 1, pp. 3-24 (2012)

Lunne, T., Robertson, P.K., Powell, J.J.M.: Cone penetration tests in geotechnical practice (1997)

The Flat Dilatometer Test (DMT) in Soil Investigation, Report of the ISSMGE, Technical Committee 16 on "Ground Property Characterization from In-Situ Testing" (2001) 